\title{
Impact of menopausal status and HER-2/neu protein on efficacy of EGFR-TKI in EGFR mutant patients with non-small cell lung cancer
}

\author{
Zi-Jun Yin',2, Hai-Yan Tu², Ming Fu³, Wen-Zhao Zhong2, She-Juan An², Hong-Hong Yan², Hua-Jun Chen², \\ Hui-Ran Lin ${ }^{4}$, Yi-Long $\mathrm{Wu}^{2}$ \\ 1. Department of Oncology, The First Affiliated Hospital, Jinan University, Guangzhou, China \\ 2. Guangdong Lung Cancer Institute, Guangdong Provincial Key Laboratory of Translational Medicine in Lung Cancer, Guangdong General Hospital and \\ Guangdong Academy of Medical Sciences, Guangzhou, China \\ 3. The First Affiliated Hospital, Jinan University, Guangzhou, China \\ 4. Laboratory Animal Management Office, Public Service Platform for Science and Technology, Shenzhen Institutes of Advanced Technology, Chinese \\ Academy of Sciences, Shenzhen, China
}

$\square$ Corresponding author: Yi-Long Wu, MD, Guangdong Lung Cancer Institute, Guangdong General Hospital and Guangdong Academy of Medical Sciences, 106 Zhongshan Er Rd, Guangzhou, Guangdong 510080, China; e-mail: syylwu@live.cn

(c) Ivyspring International Publisher. This is an open access article distributed under the terms of the Creative Commons Attribution (CC BY-NC) license (https:// creativecommons.org/licenses/by-nc/4.0/). See http://ivyspring.com/terms for full terms and conditions.

Received: 2018.02.22; Accepted: 2018.06.09; Published: 2018.07.30

\begin{abstract}
Clinical studies have confirmed epidermal growth factor receptor (EGFR)-tyrosine kinase inhibitors (TKIs) used in lung cancer patients with EGFR mutations can obtain a better result, but still part of the patients with poor efficacy. EGFR mutation is highly related to female, nonsmoking and adenocarcinoma. Thus, we hypothesize that estrogen and circulating HER-2/neu protein might influence the efficacy of EGFR-TKIs in EGFR mutant patients with non-small cell lung cancer. HER-2/neu expression level of 357 eligible patients in its peripheral serum was determined using ELISA. The median progression-free survival (PFS) in five groups (premenopausal group, perimenopause group, peri to postmenopausal group, postmenopausal group and control group) was statistically difference $(P=0.025)$. Premenopausal group could predict the efficacy of EGFR-TKI $(H R=2.45,95 \% \mathrm{Cl}=1.42-4.23, P=0.001)$. No statistical significance was found in median overall survival (OS) among five groups. Optimal diagnostic cut off value of HER-2/neu was set at $47.5 \mathrm{ng} / \mathrm{ml}$, with $P=0.0607$. As the cutoff value to $47.5 \mathrm{ng} / \mathrm{ml}$ division, concentrations and menopausal status was of no significant difference $(P=0.874)$. PFS of the group below $47.5 \mathrm{ng} / \mathrm{ml}$ was significantly longer than that of the group over $47.5 \mathrm{ng} / \mathrm{ml}(P=0.000)$. HER-2/neu concentration was positively correlated with optimal efficacy $(P=0.042)$. HER-2/neu concentration over than $47.5 \mathrm{ng} / \mathrm{ml}$ was a risk factor of EGFR-TKI prognosis. Premenopausal status is an independent predictor of EGFR-TKI curative effect and circulating HER-2/neu protein is an independent prognostic factor in patients with advanced NSCLC.
\end{abstract}

Key words: menopausal status, HER-2/neu, human epidermal growth factor receptor-2, non-small-cell lung cancer, efficacy

\section{Introduction}

The frequency of epidermal growth factor receptor (EGFR) gene mutations is approximately $30 \%$ in East Asia. Such mutations are more common in females, non-smokers, and adenocarcinomas [1,2]. Epidemiologic data have suggested that lung cancer in women may possess different biological characteristics compared to men as most female lung cancer patients are never smokers [3, 4].

Some studies have shown that female hormones such as estrogen and progesterone could play a critical role in lung carcinogenesis. Previous studies have demonstrated that progesterone receptors (PR) 
and estrogen receptors (ER), especially the ER $\beta$ subtype, are expressed in human lung cancer cell lines as well as in patient derived tumors [5]. Several researches have reported that ER $\beta$ expression in NSCLC tumor samples takes up to $30 \%-60 \%$ and even higher in EGFR mutation positive NSCLC, ranging from $67 \%$ to $82 \%$ [6-8]. Additionally, there is evidence from preclinical studies that $\beta$-estradiol is a tumor promoting hormone in lung cancer derived cell lines [5] and the administration of fulvestrant, an ER angatonist, in combination with gefitinib was shown to decrease cellular proliferation in NSCLC cell lines and in tumor xenograft models [9]. A more recent publication showed that there is a cross-talk between VEGFA, EGFR and ER $\beta$ pathways and the combination of fulvestrant and vandetanib inhibited tumor growth in NSCLC xenograft models [10].

EGFR tyrosine kinase inhibitor (TKI) gefitinib, erlotinib or afatinib was effective in non-small cell lung cancer (NSCLC) with EGFR activating mutations [1,11-16]. Clinical studies have confirmed EGFR-TKIs used in patients with EGFR mutations can obtain a better result, but still part of the patients with poor efficacy. In the IPASS (Iressa Pan-Asia Study) trial, a subgroup analysis by age showed that participants $>65$ years of age derived greater benefit from gefitinib compared to those $<65$ years [1]. This discrepancy gives a hint that hormone might influence the efficacy of EGFR-TKIs treatment outcome. Moreover, some researches showed that human epidermal receptor 2 (HER2) may play an important role in the occurrence and development of lung cancer, especially when EGFR has mutated. High HER2 expression in tissues indicates adverse prognosis of early adenocarcinoma and small cell lung cancer (SCLC). Since HER2 and EGFR (HER1) are heterodimers, is it possible that their relationship can affect TKI efficacy? Can HER-2/neu be used as a biomarker of TKI efficacy? Thus, we propose a hypothesis that estrogen and HER-2/neu may be predictors of the efficacy of EGFR-TKIs. Therefore, we conducted a retrospective analysis of EGFR mutation positive NSCLC patients who received erlotinib or gefitinib to evaluate their progression free survival (PFS) by age, gender and circulating HER-2/neu to test this hypothesis.

\section{Materials and methods}

\section{Patients and age as surrogates of menopausal status}

A total of 357 eligible patients from Guangdong Lung Cancer Institute (GLCI) from April 2005 to March 2013 were included. Inclusion criteria were set as follows: 18 years old or above, positive EGFR mutation (direct sequencing method), pathological diagnosis for III B or IV NSCLC, treatment of erlotinib or gefitinib in first-line or second-line. All clinical and treatment information was collected from electronic medical records at GLCI. All tissues used for this study were from the GLCI tissue bank. EGFR mutations were detected routinely by direct sequence method.

Based on Chinese Gynecology Society Guideline [17] about age and menopausal status relationship, all female patients in our retrospective cohorts were divided into 4 groups: (1) premenopausal group, less than 45 years old; (2) perimenopause group, 45-54 years old; (3) peri to postmenopausal group, 55-64 years old; and (4) postmenopausal group, equal to or older than 65 years.

\section{Response evaluation}

The response evaluation of EGFR-TKIs was performed according to the Response Evaluation Criteria in Solid Tumors (RECIST) guidelines (ver. 1.1). Progression free survival (PFS) was calculated from the first day of treatment to the first radiological evidence of disease progression or death for any reason. Overall survival (OS) was defined as the interval from the start of TKIs to the last visit or death; data from patients who were alive at the last follow-up visit were censored. We adopted Kaplan Meier survival analysis and Cox proportional hazards regression model to assess the correlation between age and PFS. The hazard ratio (HR) and the 95\% confidence interval $(\mathrm{CI})$ were calculated using the Cox regression model.

\section{Quantification of circulating human epidermal growth factor receptor-2 (HER-2/neu) protein}

95 serum samples were obtained from the 357 patients whose serum samples have been reserved in the tissue bank of GLCI. HER-2/neu expression level in serum was determined using ELISA (HER2 ELISA kit purchased from US R\&D Company). Blood sample was collected before treatment, without chemotherapy, radiotherapy or targeted therapy in diurnal peripheral blood. Rank sum test was used to analyze the relationship between HER-2/neu expression level and EGFR mutation type. Maximum rank method from $\mathrm{R}$ software was used to calculate the optimal diagnostic cutoff value. Kaplan-Meier survival analysis and Cox proportional hazards regression model were used to evaluate the correlation between HER-2/neu expression level and PFS of EGFR-TKI.

\section{Statistical analysis}

All analyses were conducted using the SPSS software (ver. 13.0). The $P$ values were two-tailed, and 
$P$ values $<0.05$ were considered to indicate statistical significance.

\section{Results}

\section{Clinical characteristics}

357 eligible participants were divided into five groups. 43 cases in postmenopausal group (A) ,62 cases in peri to postmenopausal group (B), 54 cases in perimenopausal group (C), 28 female cases in premenopausal group (D) and 170 cases of male serve as control group (E). The main clinic pathological characteristics of the included participants were showed in Table 1.

Table 1. Clinicopathological characteristics.

\begin{tabular}{|c|c|c|c|c|c|c|}
\hline Variables & $\begin{array}{l}\text { Total } \\
(\%) \\
(\mathrm{N}=357)\end{array}$ & $\begin{array}{l}\text { Group A } \\
(\%) \\
(\mathrm{N}=43)\end{array}$ & $\begin{array}{l}\text { Group B } \\
(\%) \\
(\mathrm{N}=62)\end{array}$ & $\begin{array}{l}\text { Group C } \\
(\%) \\
(\mathrm{N}=54)\end{array}$ & $\begin{array}{l}\text { Group D } \\
(\%) \\
(\mathrm{N}=28)\end{array}$ & $\begin{array}{l}\text { Group E } \\
(\%) \\
(\mathrm{N}=170)\end{array}$ \\
\hline \multicolumn{7}{|c|}{ Age of diagnosis } \\
\hline Median & 57 & 70 & 60 & 51 & 40.5 & 58 \\
\hline Range & $27-85$ & $65-84$ & $55-64$ & $45-54$ & $27-44$ & $31-85$ \\
\hline \multicolumn{7}{|c|}{ Smoking history } \\
\hline Never-smoker & $250(70.0)$ & $41(95.3)$ & $62(100.0)$ & $52(96.2)$ & $28(100.0)$ & $67(39.4)$ \\
\hline Ever-smoker & $107(30.0)$ & $2(4.7)$ & $0(0)$ & $2(3.8)$ & $0(0)$ & $103(60.6)$ \\
\hline \multicolumn{7}{|c|}{ Pathology type } \\
\hline $\mathrm{ADC}$ & $339(94.9)$ & $42(97.6)$ & $58(93.5)$ & $53(98.1)$ & $27(96.4)$ & $159(93.5)$ \\
\hline Others & $18(5.1)$ & $1(2.4)$ & $4(6.5)$ & $1(1.9)$ & $1(3.6)$ & $11(6.5)$ \\
\hline \multicolumn{7}{|l|}{ ECOG status } \\
\hline $0-1$ & $341(95.5)$ & $42(97.6)$ & $61(98.3)$ & $51(94.4)$ & $24(85.7)$ & 163(95.8) \\
\hline$>1$ & $16(4.5)$ & $1(2.4)$ & $1(1.7)$ & $3(5.6)$ & $4(14.3)$ & $7(4.2)$ \\
\hline \multicolumn{7}{|l|}{ Stage } \\
\hline IIIB & $10(2.9)$ & $0(0)$ & $2(3.2)$ & $2(3.7)$ & $0(0)$ & $6(3.5)$ \\
\hline IV & $347(97.1)$ & $43(100.0)$ & $60(96.8)$ & $52(96.3)$ & $28(100.0)$ & $164(96.5)$ \\
\hline \multicolumn{7}{|c|}{ Types of EGFR mutation } \\
\hline 19 deletion & 191(53.5) & $22(51.2)$ & $32(51.6)$ & $33(61.1)$ & $20(72.0)$ & $84(49.4)$ \\
\hline $21 \mathrm{~L} 858 \mathrm{R}$ & $151(42.3)$ & $20(46.5)$ & $27(43.6)$ & $21(38.9)$ & $8(28.0)$ & $75(44.1)$ \\
\hline Others & $15(4.2)$ & $1(82.3)$ & $3(4.8)$ & $0(0)$ & $0(0)$ & $11(6.5)$ \\
\hline \multicolumn{7}{|l|}{ Lines of TKI } \\
\hline First-line & $242(67.8)$ & $34(79.1)$ & $43(69.4)$ & $20(37.0)$ & $16(57.1)$ & $129(75.9)$ \\
\hline Second-line & $115(32.2)$ & $9(20.9)$ & 19(30.6) & $34(63.0)$ & $12(42.9)$ & $41(24.1)$ \\
\hline \multicolumn{7}{|l|}{ Types of TKI } \\
\hline Gefitinib & 214(59.9) & $29(67.4)$ & $44(71.0)$ & $35(64.8)$ & $21(75.0)$ & $85(50.0)$ \\
\hline Erlotinib & $143(40.1)$ & $14(32.6)$ & $18(29.0)$ & $19(23.2)$ & $7(25.0)$ & $85(50.0)$ \\
\hline
\end{tabular}

\section{Efficacy response rate of EGFR-TKI in different menopausal status}

A total of 357 participants were available for response evaluation. The efficacy of EGFR-TKI includes complete response (CR), partial response (PR), stable disease (SD) and no clinical benefit, defined as progression disease (PD). We use the nonparametric test analysis of response rate. There were statistically differences between the five groups $(P<0.001)$ (Table 2). The median PFS of group A was 7.4 months, median PFS of group B was 12.7 months, median PFS of group C was 10.0 months and median PFS of group D was 13.7 months. PFS in five groups was statistically difference $(P=0.025)$ (Figure $1 \mathrm{~A})$.
Table 2. Menopausal status on the response rate of EGFR-TKI $(\mathrm{N}=357)$.

\begin{tabular}{llll}
\hline Characteristic & $\mathrm{Nb}(\%)$ & $\mathrm{DCR}(\%)$ & $\mathrm{PD}(\%)$ \\
\hline All patients & $357(100.0)$ & 79.6 & $73(20.4)$ \\
Postmenopause & $43(12.1)$ & 81.4 & $8(18.6)$ \\
Peri to postmenopausal & $62(17.4)$ & 85.5 & $9(14.5)$ \\
Perimenopause & $54(15.1)$ & 79.6 & $11(20.4)$ \\
Premenopausal & $28(7.8)$ & 60.7 & $11(39.3)$ \\
Male & $170(47.6)$ & 80 & $34(20)$ \\
\hline
\end{tabular}

No statistical significance was observed in median overall survival (OS) among five groups $(P=$ 0.209) (Figure 1B).

Cox proportional hazards regression model was used to assess the associations. The covariates included first vs. second line, performance score at the start of treatment $(0,1,2)$, menopausal status. Multivariable Cox regression analysis showed that menopausal status and sensitive mutations were independent factors. Premenopausal group could predict the efficacy of EGFR-TKI $(H R=2.45,95 \% \mathrm{CI}$ : 1.42-4.23, $P=0.001$ ) (Table 3).

Table 3. Progression free survival by menopausal status

\begin{tabular}{lllll}
\hline & \# cases & Hazard Ratio & 95\% CI & $P$ \\
\hline postmenopausal & 43 & 1.0 (ref) & -- & 0.016 \\
peri to postmenopausal & 62 & 1.76 & $1.12-2.75$ & 0.014 \\
perimenopausal & 54 & 1.38 & $0.86-2.20$ & 0.182 \\
Premenopausal & 28 & 2.45 & $1.42-4.23$ & 0.001 \\
Men & 170 & 1.42 & $0.96-2.11$ & 0.076 \\
& & $P$-trend $=0.009$ & \\
\hline
\end{tabular}

\section{HER-2/neu serum levels}

95 serum samples were extracted from the involved 357 patients. Patients who donated serum samples in the study included 56 females and 39 males, with a medium age of 56 years (33-77 years range). 87 patients (91.6\%) had adenocarcinoma, and 8 patients $(7.4 \%)$ had a squamous or other histologic subtype. The HER-2/neu median concentration of the overall baseline was $27.11 \mathrm{ng} / \mathrm{ml} \quad(10.29-288.03$ $\mathrm{ng} / \mathrm{ml}$ ), while the serum concentration of HER-2/neu was not significantly correlated with age, gender, histological classification, smoking status and EGFR mutation type. Optimal diagnostic cut off value of HER-2/neu was set at $47.5 \mathrm{ng} / \mathrm{ml}$, with $P=0.0607$ as analyzed using R software. As the cutoff value to 47.5 $\mathrm{ng} / \mathrm{ml}$ division, concentrations and menopausal status was of no significant difference $(P=0.874)$ (Table 4).

PFS of the group below $47.5 \mathrm{ng} / \mathrm{ml}$ was significantly different from that of the group over 47.5 $\mathrm{ng} / \mathrm{ml}(9.2$ months vs. 5.6 months, $P=0.000)$ (Figure 2). HER-2/neu concentration was positively correlated with optimal efficacy $(P=0.042)$. Multi-factor COX regression model showed a significant difference between the PFS of the two 
groups divided by the critical point of $47.5 \mathrm{ng} / \mathrm{ml}$ and PFS of EGFR-TKI ( $\mathrm{HR}=3.49,95 \% \mathrm{CI}=1.92-6.34, P=$ 0.000) (Table 5). HER2 concentration over than 47.5 $\mathrm{ng} / \mathrm{ml}$ was a risk factor of EGFR-TKI prognosis. As too much data on the overall survival time were deleted, OS showed no statistical difference.

Table 4. Patients characteristics according to HER-2/neu serum concentration

\begin{tabular}{lll}
\hline Characteristic & $\begin{array}{l}\geq 47.5 \mathrm{ng} / \mathrm{ml} \\
(\mathrm{No} .) \%\end{array}$ & $\begin{array}{l}<47.5 \mathrm{ng} / \mathrm{ml} \\
(\mathrm{No} .) \%\end{array}$ \\
\hline $\begin{array}{l}\text { Total } \\
\text { Gender }\end{array}$ & 19 & 76 \\
Males & $5(26.3)$ & $34(44.7)$ \\
Females & $14(73.7)$ & $42(55.3)$ \\
Age (yrs) & & \\
Median (range) & 57 & 56 \\
Smoking & & \\
Nonsmokers & $12(63.2)$ & $57(75)$ \\
Smokers & $7(36.8)$ & $19(25)$ \\
Histology & & \\
\hline
\end{tabular}

\begin{tabular}{lll}
\hline Characteristic & $\begin{array}{l}\geq 47.5 \mathrm{ng} / \mathrm{ml} \\
(\mathrm{No} .) \%\end{array}$ & $\begin{array}{l}<47.5 \mathrm{ng} / \mathrm{ml} \\
(\mathrm{No} .) \%\end{array}$ \\
\hline $\begin{array}{l}\text { Adenocarcinoma } \\
\text { Squamous/others }\end{array}$ & $\begin{array}{l}17(89.5) \\
2(10.5)\end{array}$ & $\begin{array}{l}70(92.1) \\
\text { Tumor stage }\end{array}$ \\
III & $2(10.9)$ & \\
IV & $17(89.5)$ & $3(3.9)$ \\
Performance status & $17(89.5)$ & $73(96.1)$ \\
$0-1$ & $2(10.5)$ & $73(96.1)$ \\
2 & & $3(3.9)$ \\
EGFR mutation & $19(100 \%)$ & $72(94.7)$ \\
Sensitive mut & $0(0)$ & $4(5.3)$ \\
Insensitive mut & & \\
The line of TKI & $14(73.7)$ & $48(63.2)$ \\
First line TKI & $5(26.3)$ & $28(36.8)$ \\
Second line TKI & & \\
Response to treatment & $11(57.9)$ & $28(36.8)$ \\
SD, PD & $8(42.1)$ & $48(63.2)$ \\
CR, PR &
\end{tabular}

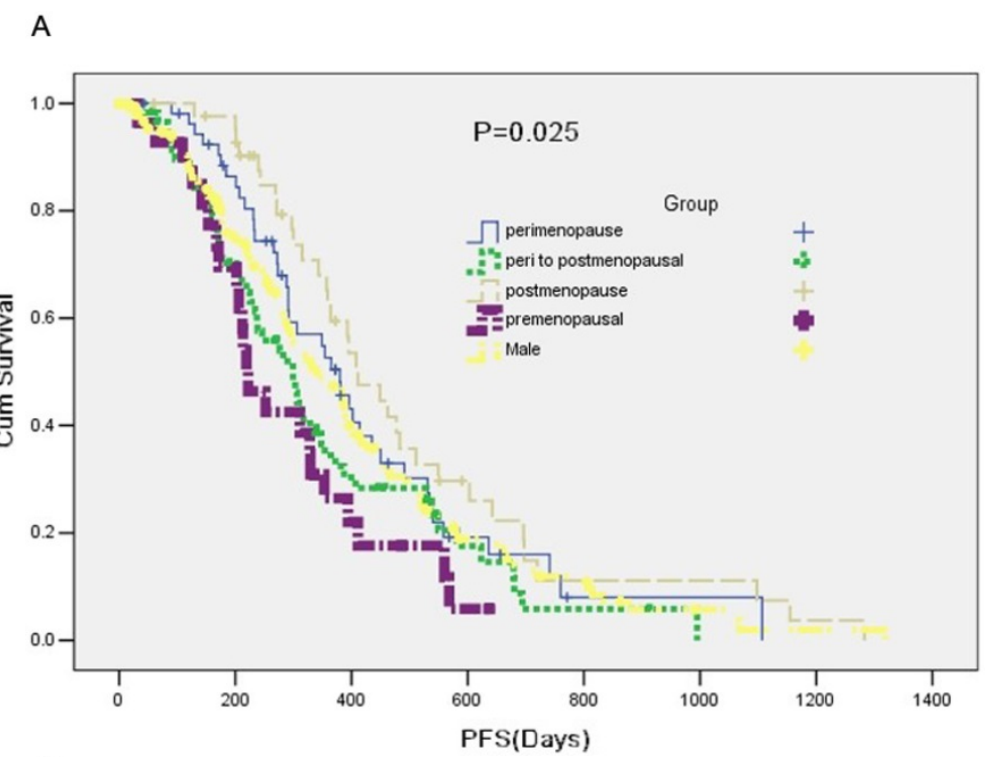

B

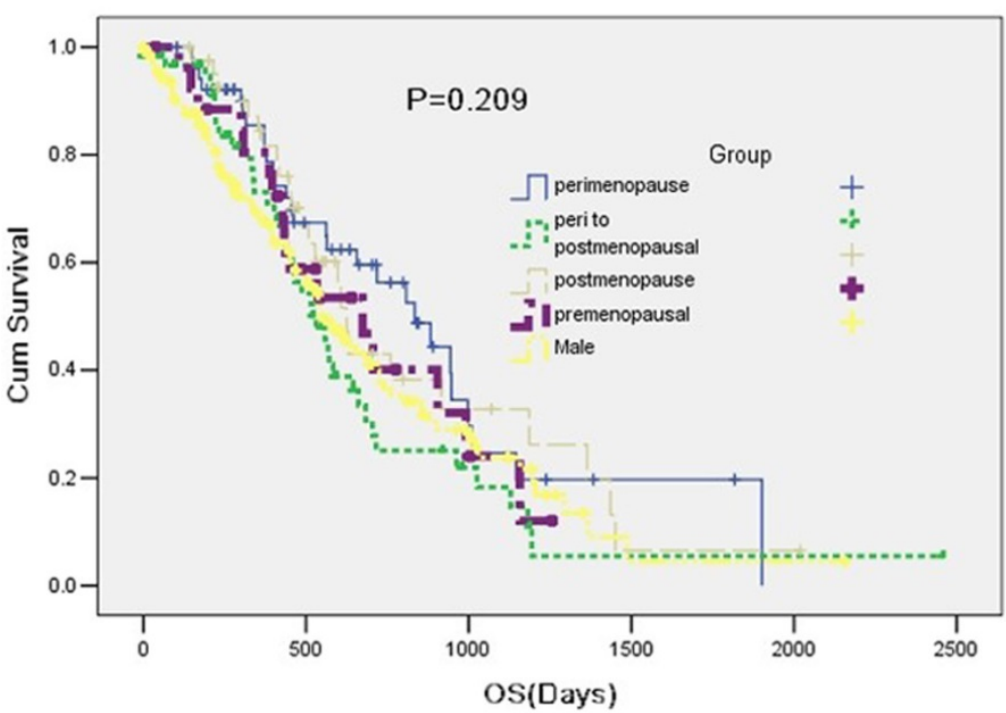

Figure 1. A: A Kaplan-Meier curve of the data to estimate the distributions of time-to-event outcomes. B: Overall survival (OS) between groups. 


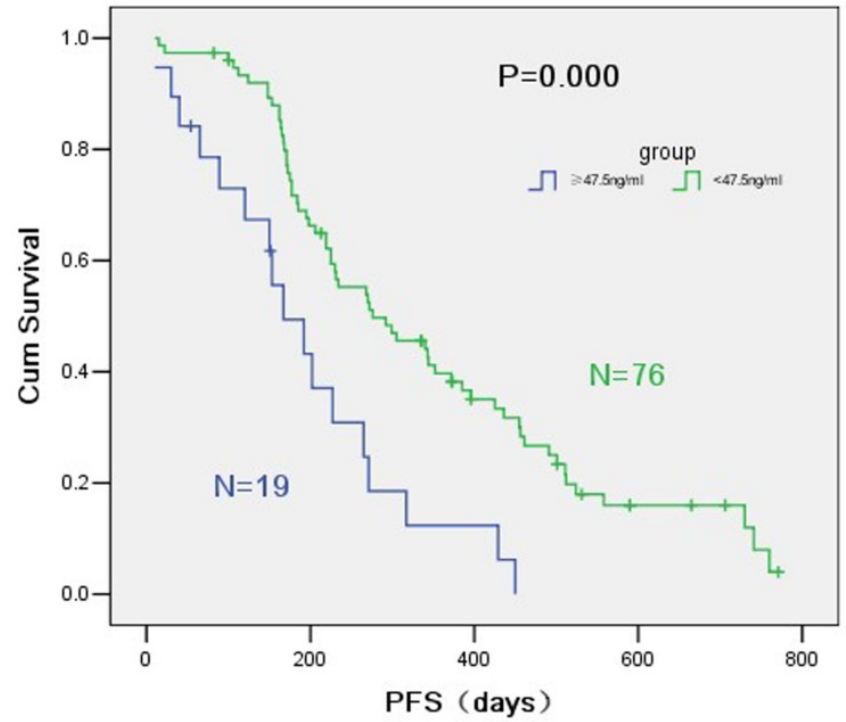

Figure 2. Survival curves according to $R$ software of HER-2/neu serum concentration.

Table 5. Progression free survival by HER-2/neu serum concentration.

\begin{tabular}{lllll}
\hline & \# cases & Hazard Ratio & 95\% CI & $P$ \\
\hline$<47.5 \mathrm{ng} / \mathrm{ml}$ (No.)\% & 76 & 1.0 (ref) & -- & -- \\
$\geq 47.5 \mathrm{ng} / \mathrm{m}(\mathrm{No}) \%$. & 19 & 3.49 & $1.92-6.34$ & 0.000 \\
\hline
\end{tabular}

\section{Discussion}

The current study provides evidence that menopausal status can represent a new, independent, biologic prognostic factor of EGFR-TKI in EGFR mutant patients with NSCLC. To our knowledge, this is by far the first study regarding the effect of menopausal status and circulating human epidermal growth factor receptor-2 protein on efficacy of EGFR-TKI in EGFR mutant patients with NSCLC.

Our data showed that median PFS was 7.4 months for patients with premenopausal status compared with 13.7 months for patients with postmenopausal status $(H R=2.45,95 \% \mathrm{CI}=1.42-4.23$, $P=0.001)$. This result firstly indicated that premenopausal status is an independent negative predictor of EGFR-TKI efficacy on EGFR mutant female patients. Although there is a lack of literatures referring to this question, a subgroup analysis by age in the IPASS trial showed that participants $>65$ years old got increased benefit from gefitinib compared to those < 65 years [1]. Our data also verified premenopausal female had poorer prognosis under EGFR-TKI treatment.

This study may provide the basis for premenopausal patients with hormone therapy in EGFR mutant patients with non-small cell lung cancer. In estrogen treatments related to lung cancer, Stabile et al. [12] reported an animal experiment that used the combination of EGFR inhibitors and
Fulvestrant to treat mouse models with human tumor grafts. The combined treatment reduced the tumor volume by $60 \%$, while the tumor volume was reduced by $49 \%$ and $32 \%$, respectively, after single drug applications. For Gefitinib-resistant NSCLC cell lines, combination treatment could significantly rescue lung adenocarcinoma cell proliferation [19]. This would provide the basis for using Gefitinib-estrogen combined treatment on advanced NSCLC. Clinically, EGFR/ER double-inhibition experiments have achieved a certain extent of success. There have been clinical studies on treating NSCLC in menopausal women using Fulvestrant combined with Gefitinib, who showed good tolerance towards $250 \mathrm{mg} / \mathrm{month}$ of intramuscular injections [20].

Many clinical features of lung cancer are different in women and men. Sex steroid hormones exert effects in non-reproductive organs, such as the lungs. The association between menstrual and childbearing factors and the risk of lung cancer among women is still debated. Soumaya [21] showed that peri/postmenopausal women were at higher risk compared to premenopausal. Premenopausal women showed increased risks associated with parity. More investigations in large well-designed studies are needed to confirm these findings and to clarify the underlying mechanisms of gender differences in lung cancer risk. This large sample of meta-analysis also validates the feasibility of our research. The use of age as a proxy for menopause status was a necessity of the study design, the significant confounding factor of age; indeed older men also had a significantly worse prognosis compared to younger men [22]. Perhaps the inclusion of age as an independent continuous variable and the comparison of its effects in men and women might reveal a more significant difference, aided by the large sample size of the study. This topic is an extremely important one, and large observational studies developments in the management of non-small cell lung cancer. Our division is based strictly on the menopause guidelines of the Chinese Medical Association of China and is based on data from a large sample of Chinese people.

The serum HER-2/neu content in the peripheral blood of newly-diagnosed advanced NSCLC patients with EGFR mutation was tested for the first time. Median serum HER-2/neu concentration was 27.11 $\mathrm{ng} / \mathrm{mL}$ (range 10.29-288.03 ng/ml). Our study showed that high serum HER-2/neu concentration of untreated advanced NSCLC patients was correlated with poor efficacy of EGFR-TKI. Combined testing of both EGFR mutation and HER2 protein expression level in peripheral blood may better predict the efficacy of EGFR-TKI on advanced NSCLC. Research data showed that the concentration of HER2 in breast 
cancer patient's blood elevate to $15-75 \mathrm{ng} / \mathrm{mL}$ compared to $2-15 \mathrm{ng} / \mathrm{mL}$ in normal individuals [23]. The amount of HER2 in the blood of healthy people is 2-15 ng/mL, which can explain the high expression of HER2 in cancer patients.

The literature indicates that gefitinib not only blocks signals by suppressing EGFR-TK activation, but also further suppresses downstream signaling by affecting the interactions between erbB family members, especially EGFR, HER2 and HER3.Researchers have currently reached a consensus that gene mutation on the determinant region of EGFR-TK is closely related to efficacy [24]. However, EGFR mutation cannot completely predict the efficacy of gefitinib, and the reason is suspected to because of the complex interactions between EGFR and other members of erbB family. Compared with other members or heterodimers activated from other members, EGFR homodimer has higher receptor activity and better signal transduction capacity, hence, activity of a single member cannot represent the overall condition of a signaling pathway $[25,26]$.

Our findings are consistent with a previous study on serum HER2 of advanced NSCLC patients. Ardizzoni et al. [27] designed a study to assess the potential value of measuring serum levels of HER-2/neu oncoprotein in predicting response to treatment and survival in patients with locally advanced and metastatic non-small cell lung carcinoma. They used ELISA to determine serum HER2 concentration in peripheral blood of 86 newly-diagnosed IIIB/IV NSCLC patients undergoing platinum-based standard chemotherapy. They found that high pretreatment levels of HER-2/neu oncoprotein are associated with an adverse prognostic impact on survival in patients with locally advanced or metastatic non-small cell lung carcinoma.

We did not continuously monitor serum dynamic changes since it was reported to be of no significance in many studies. In a study [28] whereby the targeted drug Iressa was used on advanced NSCLC patients, 3 blood samples were collected at 1 week before using the drug, 28 days at stable concentration and at optimal efficacy during CT evaluation. ELISA HER-2/neu serum expressions of the 3 samples showed no statistical difference with a median concentration of $13.7 \mathrm{ng} / \mathrm{ml}$. This was close to the $27.11 \mathrm{ng} / \mathrm{ml}$ result obtained in our study, while the deviation in values might be related to different patient inclusion criteria and different experimental techniques. Although there have been studies indicating that there is no consistency between serum and tissue levels, this still needs to be verified using histology.
Despite this is the first study investigating the role of the menopausal status and circulating human epidermal growth factor receptor-2 protein in influencing efficacy of EGFR-TKI in EGFR mutant patients with non-small cell lung cancer, several limitations still exist. As a retrospective design, the study based on age categories suggested shorter overall survival. Lung cancer found in young women group is always advanced and unresectable which may be related to higher hormone levels promoting tumor growth in vivo. Molecular mechanism about hormone levels and EGFR-TKI pathway remained elusive. Therefore, larger samples and further molecular mechanism researches are needed to support such hypothesis. Hormone level detection may be more meaningful for diagnosis such as ER, PR, HER2. The changes of these markers should be followed before and after the treatment. Some studies have demonstrated its lung cancer-promoting effect, but as of early surgical specimens [22]. Therefore, further investigations into underlying molecular mechanisms are warranted. From this and other studies, it is not possible to know whether circulating HER-2/neu protein levels are correlated with tissue overexpression or which of the two tests is most useful for assessing prognosis in patients with advanced NSCLC. Therefore, we need to use tissue samples to verify the correlation between the circulating HER-2/neu protein and the tissue expression.

In conclusion, the results from this study suggest that premenopausal status and circulating HER-2/neu are independent predictors of EGFR-TKI efficacy in EGFR mutant patients with non-small cell lung cancer. Prospective data and further investigations into underlying molecular mechanisms are warranted.

\section{Acknowledgments}

This study was supported by grants from the Special Fund for Research in the Public Interest from National Health and Family Planning Commission of PRC (Grant No.201402031) and Project of National Natural Science Foundation (Grant No.81372285).

\section{Competing Interests}

The authors have declared that no competing interest exists.

\section{References}

1. Asaka S, Yoshizawa A, Saito K, et al. Rapid point-of-care testing for epidermal growth factor receptor gene mutations in patients with lung cancer using cell-free DNA from cytology specimen supernatants. Int J Oncol. 2018; 27.

2. Rosell R, Moran T, Queralt C, et al. Screening for epidermal growth factor receptor mutations in lung cancer. N Engl J Med. 2009; 361: 958-67.

3. Siegel RL, Miller KD, Jemal A, et al. Cancer statistics, 2018. CA Cancer J Clin. 2018; 68: 7-30. 
4. Jemal, A, Bray F, Ferlay J, et al. Global cancer statistics. CA Cancer J Clin. 2011; 61: 69-90.

5. Stabile LP, Davis AL, Gubish CT, et al. Human non-small cell lung tumors and cells derived from normal lung express both estrogen receptor alpha and beta and show biological responses to estrogen. Cancer Res. 2002; 62: 2141-50.

6. Raso MG, Behrens C, Herynk MH, et al. Immunohistochemical expression of estrogen and progesterone receptors identifies a subset of NSCLCs and correlates with EGFR mutation. Clin Cancer Res. 2009; 15: 5359-68.

7. Rouquette I, Cances VL, Allera C, et al. Characteristics of lung cancer in women: importance of hormonal and growth factors. Lung Cancer. 2012; 76: 280-5.

8. Nose N, Sugio K, Oyama T, et al. Association between estrogen receptor-beta expression and epidermal growth factor receptor mutation in the postoperative prognosis of adenocarcinoma of the lung. J Clin Oncol. 2009; 27: 411-7.

9. Stabile LP, Lyker JS, Gubish CT, et al. Combined targeting of the estrogen receptor and the epidermal growth factor receptor in non-small cell lung cancer shows enhanced antiproliferative effects. Cancer Res. 2005; 65: 1459-70.

10. Siegfried JM, Gubish CT, Rothstein ME, et al. Combining the multitargeted tyrosine kinase inhibitor vandetanib with the antiestrogen fulvestrant enhances its antitumor effect in non-small cell lung cancer. J Thorac Oncol. 2012; 7: 485-95.

11. Mitsudomi T, Morita S, Yatabe Y, et al. Gefitinib versus cisplatin plus docetaxel in patients with non-small-cell lung cancer harbouring mutations of the epidermal growth factor receptor (WJTOG3405): an open label, randomised phase 3 trial. Lancet Oncol. 2010; 11: 121-8.

12. Zhou, $\mathrm{C}, \mathrm{Wu} \mathrm{YL}$, Chen $\mathrm{G}$, et al. Erlotinib versus chemotherapy as first-line treatment for patients with advanced EGFR mutation-positive non-small-cell lung cancer (OPTIMAL, CTONG-0802): a multicentre, open-label, randomised, phase 3 study. Lancet Oncol. 2011; 12: 735-42.

13. Rosell $R$, Carcereny $E$ Gervais $R$ et al. Erlotinib versus standard chemotherapy as first-line treatment for European patients with advanced EGFR mutation-positive non-small-cell lung cancer (EURTAC): a multicentre, open-label, randomised phase 3 trial. Lancet Oncol. 2012; 13: 239-46.

14. Yang JC, Hirsh V, Schuler $\mathrm{M}$, et al, Symptom control and quality of life in LUX-Lung 3: a phase III study of afatinib or cisplatin/pemetrexed in patients with advanced lung adenocarcinoma with EGFR mutations. J Clin Oncol. 2013; 31: 3342-50.

15. Sequist LV, Yang JC, Yamamoto N, et al. Phase III study of afatinib or cisplatin plus pemetrexed in patients with metastatic lung adenocarcinoma with EGFR mutations. J Clin Oncol. 2013; 31: 3327-34.

16. $\mathrm{Wu} Y \mathrm{~L}, \mathrm{Zhou} \mathrm{C}, \mathrm{Hu} \mathrm{CP}$, et al. Afatinib versus cisplatin plus gemcitabine for first-line treatment of Asian patients with advanced non-small-cell lung cancer harbouring EGFR mutations (LUX-Lung 6): an open-label, randomised phase 3 trial. Lancet Oncol. 2014; 15: 213-22.

17. Yu Q. The Chinese medical association branch of obstetrics and gynecology of the postmenopausal group, postmenopausal hormone replacement therapy related specifications of the diagnosis and treatment process. Chin J Obstet Gynecol. 2013; 48: 155-58.

18. Zhou Q, Zhang XC, Chen ZH, et al. Relative abundance of EGFR mutations predicts benefit from gefitinib treatment for advanced non-small-cell lung cancer. J Clin Oncol. 2011; 29: 3316-21.

19. Xu R, Shen H, Guo R, et al. Combine therapy of gefitinib and fulvestrant enhances antitumor effects on NSCLC cell lines with acquired resistance to gefitinib. Biomed Pharmacother. 2012; 66: 384-9.

20. Traynor AM, Schiller JH, Stabile LP, et al. Pilot study of gefitinib and fulvestrant in the treatment of post-menopausal women with advanced non-small cell lung cancer. Lung Cancer. 2009; 64: 51-9.

21. Soumaya BK,Monica N, Alexandra $\mathrm{P}$, et al. Menstrualand reproductive factors and lung cancer risk: A pooled analysis from the international lung cancer consortium. Int J Cancer. 2017; 141: 309-23.

22. Birdas TJ. Menopausal status and non-small cell lung cancer. Ann Thorac Surg. 2005; 80: 789-90.

23. Shen C, Zeng K, Luo J, et al. Self-Assembled DNA Generated Electric Current Biosensor for HER2 Analysis. Anal Chem. 2017; 89: 10264-9.

24. Sun $\mathrm{HB}$, Zheng $\mathrm{Y}, \mathrm{Ou} \mathrm{W}$, et al. Association between hormone receptor expression and epidermal growth factor receptor mutation in patients operated on for non-small cell lung cancer. Ann Thorac Surg. 2011; 91: 1562-7.

25. Fujimoto N, Wislez M, Zhang J, et al. High expression of ErbB family members and their ligands in lung adenocarcinomas that are sensitive to inhibition of epidermal growth factor receptor. Cancer Res. 2005; 65: 11478-85.

26. Sequist LV, Martins RG, Spigel D, et al. First-line gefitinib in patients with advanced non-small-cell lung cancer harboring somatic EGFR mutations. J Clin Oncol. 2008; 26: 2442-9.

27. Ardizzoni A, Cafferata MA, Paganuzzi M, et al. Study of pretreatment serum levels of HER-2/neu oncoprotein as a prognostic and predictive factor in patients with advanced nonsmall cell lung carcinoma. Cancer. 2001; 92: 1896-904.

28. Gregorc V, Ceresoli GL, Floriani I, et al. Effects of gefitinib on serum epidermal growth factor receptor and HER2 in patients with advanced non-small cell lung cancer. Clin Cancer Res. 2004; 10: 6006-12. 